\title{
The Elasticity of Substitution and Characteristics of New Investments
}

\author{
Carl-Gustav Melén \\ Department of Economics, Dalarna University, Borlänge, Sweden \\ Email: cgm@du.se
}

Received November 28, 2011; revised January 12, 2012; accepted January 22, 2012

\begin{abstract}
Changes in the interest rate and the capital cost will influence important characteristics of investments, such as the expected life time, the factor intensity and the factor productivity of new capital goods. When Harrod-neutral technical progress is endogenous and variable, an increased interest rate will lower the lifetime as well as the factor intensity of the capital good in the Cobb-Douglas case, while there will be a reversed outcome when the substitutability between factor inputs is low. The latter outcome can be interpreted in terms of a reswitching process, that is, one identical factor intensity can arise at two different factor price ratios.
\end{abstract}

Keywords: Technical Progress; Optimal Lifetime; Factor Intensity; Productivity

\section{Introduction}

One of the most important decisions the firm has to consider is when and how to invest in new capital. These decisions concern activities both today as well as activeties tomorrow. The decision of investments deals with revenues and costs, but these concepts can be transformed into productivity and capital intensity measures, i.e. the characteristics of the new investment.

In this study the investments' characteristics will be more thoroughly investigated when the interest rate and the value of the elasticity of substitution are changed. It will be shown that the value of elasticity of substitution will have a major impact on the characteristics of investment when the interest rate changes.

An investment in a capital good can be described by a number of characteristics, such as the productivity, factor equipment and length of life while the technology embodied in an investment, is characterized by a labouraugmenting factor.

Firms will in general deviate quite substantially with respect to labour productivity and factor intensity (Haltiwanger et al. [1], Baily et al. [2]). To some extent this can be taken into consideration by using a production function with different elasticity of substitution.

It has been shown that if a firm implements a higher elasticity of substitution in production, it will show a higher productivity (Papageorgiou and Saam [3]. Furthermore, Klump and de La Grandville [4] show that the productivity is an increasing function of the elasticity of substitution. The explanation to this outcome is that higher elasticity of substitution implies a higher flexibility and larger substitutability between factor inputs in production.

Studies show also that the elasticity of substitution is not constant over time, but can vary to a large extent (Miyagiwa and Papageorgiou [5], Duffy and Papageorgiou [6], Pereira [7]). This remark was already given by Arrow, Chenery, Minhas and Solow [8], when they introduced the CES-function, but still, many economists use the Cobb-Douglas function and some support for that function can be found in Kaldor's [9] stylized facts from 1961 and Berndt [10].

In this study production functions for new investments will be used, which means that only a minor part of the capital stock will be studied at a given point of time. The new investment can be designed with various capital/labour ratios, but when the investment decision has been made the investment is assumed to have fixed factor intensity over the investment's total life time (Gilchrist and Williams [11], Johansen [12], Lasky [13], Salter [14], Solow [15]). Thus, each vintage of investment is assumed to be of putty-clay type, an assumption quite common in a vintage model. Further, there is an assumption that each vintage is characterized by embodied labour-augmenting (Harrod-neutral) technical progress.

In the following sections a partial equilibrium model will be presented and the aim of the study is to investigate the firms' investment behaviour in a neoclassical setting. Perfect capital markets are assumed to exist and firms act as price takers in all markets. The model assumes intertemporal optimization in the meaning that the 
agents choose the level of investment which will maximize the expected discounted profits.

In the study a number of simulations will be performed where the equilibrium of the model will be investigated when the interest rate changes at different values of the elasticity of substitution.

The main findings are that the effects of a change in the interest rate depend partly on the value of the elasticity of substitution, partly on the existence of technical progress.

With no technical progress an increased interest rate will lower the capital intensity and the labour productiveity at the current period.

In the case when the labour-augmenting factor is determined within the model and becomes an endogenous variable, an increased interest rate will in the CobbDouglas case lower the factor intensity and productivity at the current period, while there will be a reversed outcome when there is low substitutability between the factor inputs.

The latter outcome can be seen as a reswitching phenomenon $^{1}$, i.e. the same factor intensity can arise at two different factor price ratios (Robinson [17], Samuelson [18]). However, the model generates two types of reswitching. It can be shown that, at a specific elasticity of substitution, two different factor price ratios will generate the same labour productivity, while at a lower elasticity of substitution two different factor price ratios will generate the same factor intensity.

The reswitching debate has been continuing since the 50s. In the 60s there was mainly a discussion of the theoretical possibility of reswitching, while in the last decade the focus more has been on empirical results and Han and Schefold [19] show the existence of reswitching processes by using input-output data for 9 countries and for the period 1968 - 1990.

A reswitching process indicates under specific conditions an upward-sloping demand curve for capital. Acemoglu [20] shows that an upward-sloping demand curve can arise if the production function fails to be jointly concave in input factors and technology. This outcome can occur when decision about factor inputs and technology are made by different actors in the economy.

\section{The Method of Setting the Model}

\subsection{Production and Wage Costs}

The entrepreneur calculates with a maintenance-cost during the investment's length of life.

$$
w_{t} l_{t} \int_{t}^{t+n} e^{c(v-t)} \mathrm{d} v
$$

${ }^{1}$ The literature on reswitching processes is vast and a comprehensive overview of the phenomenon can be found in Kurz [16]. where $n$ is the planned length of life of the capital-good, invested at time $t, w$ is the wage-rate, $l$ is employment and $c$ is the maintenance cost factor.

Net present value of an investment can be written

$$
\int_{t}^{t+n}\left\{p_{t} q_{t}-w_{t} l_{t} e^{c(v-t)}\right\} e^{-r(v-t)} \mathrm{d} v-p_{t}^{k} k_{t}
$$

where $q$ is the production in terms of value added, $p$ is the price of the product, $k$ is the volume of investment and $p^{k}$ is the price of the investment good.

\subsection{The Scrapping Decision and the Expected Lifetime}

The scrapping condition can be found by differentiation the net present value (2) with respect to the expected lifetime of the investment. Dropping the time notation and assuming $p=1$, the first order condition for an optimal expected lifetime becomes

$$
q / l=w e^{c n}
$$

Figure 1 shows the baseline equilibrium when $w=1$ and $c=0.04$.

The difference between expected productivity and expected wage cost over the lifetime for the investment is the quasi-rent and the discounted value equals the capital requirement per hour. The production plant is planned to shut down when the expected value of the production equals the expected wage cost at period $t+n$.

\subsection{Marginal Product of Capital}

The model uses a CES-production function with a labour-augmenting factor, $\lambda$.

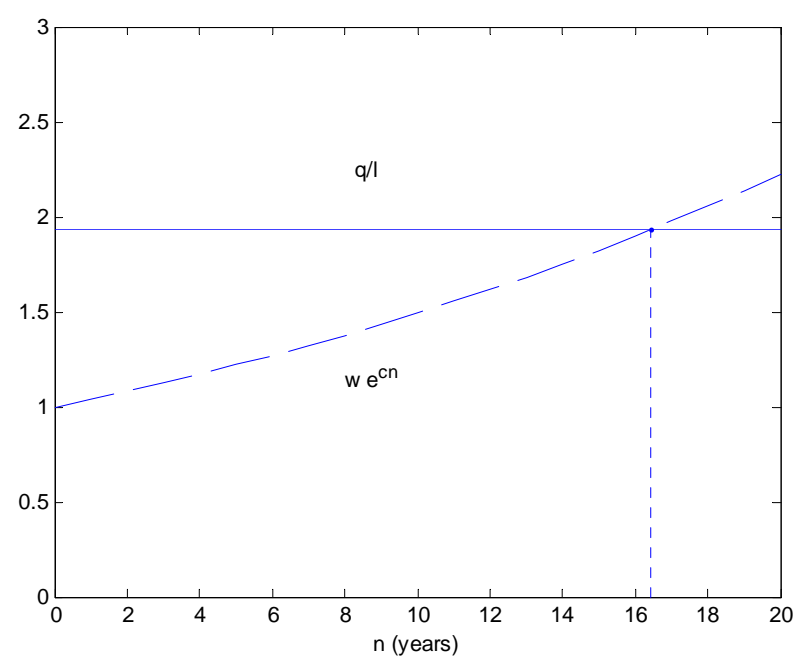

Figure 1. The ex ante length of life $\mathrm{e}^{2}$ Baseline scenario: $w=1$, $r=0.10, A=1, \rho=0.2, \delta=0.6, c=0.04$ Equilibrium values: $q / l=1.93, k / l=5.13, e^{\lambda}=1.10, n=16.45$.

${ }^{2}$ Based on a numerical simulation of the ex ante systems (8)-(11). 


$$
q_{t}=A\left[(1-\delta) k_{t}^{-\rho}+\delta\left(l_{t} e^{\lambda_{t}}\right)^{-\rho}\right]^{-1 / \rho}
$$

Maximizing the net present value with respect to the capital input, subject to the production function (4) and dropping the $t$ subscripts gives

$$
\frac{(1-\delta)(q / k)^{1+\rho}}{A^{\rho}} \int_{t}^{t+n} e^{-r(v-t)} \mathrm{d} v=p^{k}
$$

where $\frac{(1-\delta)(q / k)^{1+\rho}}{A^{\rho}}$ is the marginal product of capital.

The firms invest in new capital until the discounted expected marginal product of capital equals the price of the capital good. When $p^{k}=1$, Equation (5) becomes

$$
\mathrm{MPK}=\frac{r}{1-e^{-r n}}
$$

In equilibrium, the firm's demand for capital goods is given by the condition that the marginal product of capital at period $t$ equals $r /\left(1-e^{-r n}\right)$. A baseline equilibrium is shown in Figure 2 for $r=0.10$.

In the baseline scenario the marginal product of capital (MPK) equals 0.124 and the expected lifetime for the investment is 16.5 years.

\subsection{Marginal Product of Labour}

Maximizing the net present value with respect to input of labour and subject to the production function (4) gives

$$
\frac{\delta(q / l)^{1+\rho}}{\left(A e^{\lambda}\right)^{\rho}} \int_{t}^{t+n} e^{-r(v-t)} \mathrm{d} v=w \int_{t}^{t+n} e^{-(r-c)(v-t)} \mathrm{d} v
$$

where $\frac{\delta(q / l)^{1+\rho}}{\left(A e^{\lambda}\right)^{\rho}}$ is the marginal productivity of labour.

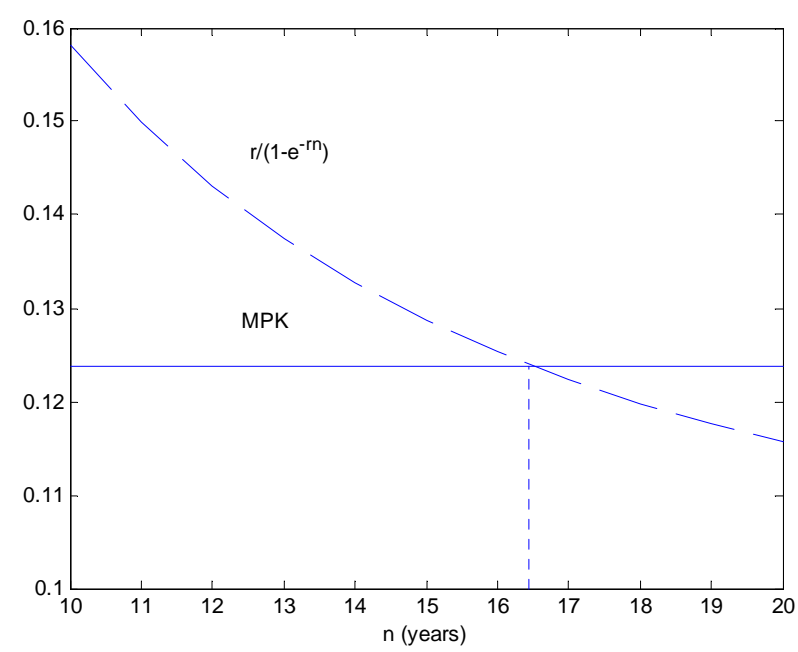

Figure 2. The marginal product of capital Baseline scenario: $w=1, r=0.10, A=1, \rho=0.2, \delta=0.6, c=0.04$ Equilibrium values: $q / l=1.93, k / l=5.13, e^{\lambda}=1.10, n=16.45$.
In equilibrium the discounted expected marginal product will be equal to the discounted expected wage costs and the baseline equilibrium is shown in Figure 3. The baseline equilibrium implies that $\mathrm{MPL}=1.30$.

\subsection{The Exante System of Equations}

The production function (4) is homogenous of degree one, and this means that we can formulate a system of equations into intensive form. Equations (2), (3) and (6) and the production function now form an ex ante system of equations.

$$
\begin{aligned}
& (q / l) \frac{1-e^{-r n}}{r}-w \frac{1-e^{-(r-c) n}}{r-c}=k / l \\
& q / l=A\left[(1-\delta)(k / l)^{-\rho}+\delta\left(e^{\lambda}\right)^{-\rho}\right]^{-1 / \rho} \\
& q / l=w e^{c n} \\
& q / l=\left[\frac{A^{\rho} r}{(1-\delta)(1-e)^{-r n}}\right]^{1 /(1+\rho)} k / l
\end{aligned}
$$

Equation (8) is the zero-profit condition, (9) is the production function and (10) and (11) are the two firstorder conditions.

The model deals with the investment decision of firms and we assume that specific characteristics, such as the labour productivity, factor intensity, the expected lifetime and the labour-augmenting factor, $\lambda$, at period $\mathrm{t}$ are endogenously determined.

Endogenous variables: $q / l, k / l, n, \lambda$

Exogenous variables: $w, r$

Parameters: $A, \delta, \rho, c$

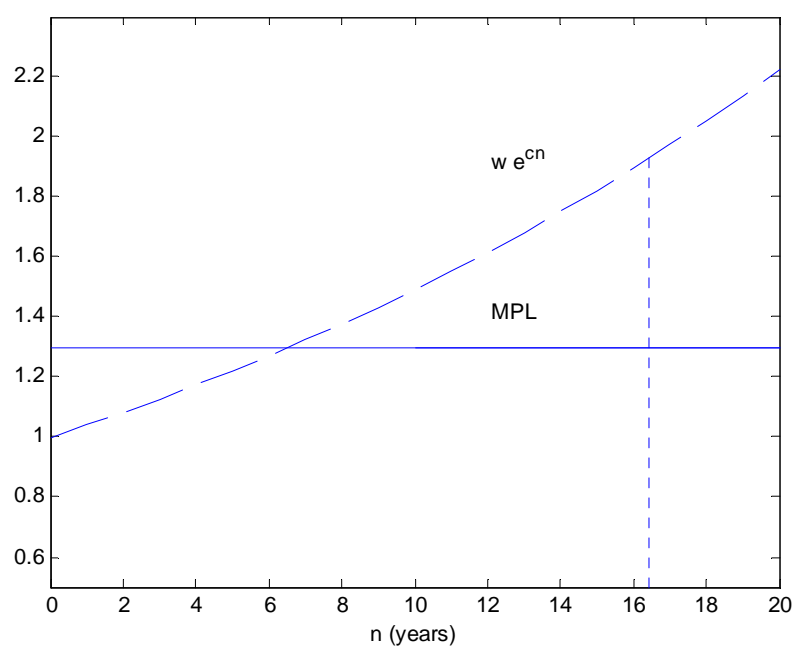

Figure 3. The marginal product of labour. Baseline scenario: $w=1, r=0.10, A=1, \rho=0.2, \delta=0.6, c=0.04$ Equilibrium: $q / l=1.93, k / l=5.13, e^{\lambda}=1.10, n=16.45$. 
The exogenous variables, $w$ and $r$ are determined by market forces, while the parameter $c$ is determined by the entrepreneur's expectations of maintenance and repair expenditure. The parameters in the production function are determined by the existing technology and can vary over the studied period as well between branches.

The labour-augmenting factor, $\lambda$, is an endogenously determined variable within the model. But, there is no cost of attaining an increase in the labour-augmenting factor, an assumption which is quite common in growth models with exogenous technical progress. Here, we assume that knowledge is a public good and firms have access to new discoveries and increases in human capital at zero cost. The interpretation of the model is that the technical progress is exogenous to the firm but endogenous to the economy.

Firms have, thus, incentives to increase the efficiency of labour above the equilibrium level of the model. However, a higher technical progress implies a higher marginal product of labour. Assuming a binding firstorder condition (7) and exogenous prices in the goods and factor markets the model gives a unique value for the labour-augmenting factor, $\lambda .^{3}$

The first-order condition (7) can be written

$$
\mathrm{MPL}=w \frac{\frac{1-e^{-(r-c) n}}{r-c}}{\frac{1-e^{-r n}}{r}}
$$

The RHS of (12) can be interpreted as the ratio of present value of an expected wage cost and present value of an expected price level, where $p=1$. Constant factor prices now imply a constant lifetime of the investment, a constant marginal product of labour and no technical progress.

However, a wage increase will create a proportionate increase in factor intensity and Harrod-neutral technical progress, which means that the model will follow a steadystate path.

The mechanism of the model can be described as a price-induced technical progress. The origin of the inducement mechanism is an article by Hicks. He wrote in Theory of wages ([21], p. 125): “... a change in the relative prices of factors of production is itself a spur to innovation...”.

Research in this area has been intensive during different periods and theoretical as well as empirical works have been presented. Ahmad [22], Hayami and Ruttan [23] and Thirtle [24] derive models where changes in relative input prices influence research and innovation activity in the economy and where the individual firm

\footnotetext{
${ }^{3} \mathrm{~A}$ higher marginal product, due to technical progress, will create incentives for the labour force to increase wages. However, a given wage and a binding first-order condition imply a limit for the change in $\lambda$.
}

chooses the appropriate new technique according to the change in factor prices. Esposito and Pierani [25] show in a model with lagged input prices that price-induced technical progress played a larger role than the autonomous technical progress in Italian agriculture, 1951-1991.

Paris [26] investigates a model, where expected relative prices enter the production function as shifter of the technology frontier. Empirical results do not reject the existence of price-induced technical progress in US agriculture between 1910 and 1990 .

The system of Equations (8)-(11) gives unique solutions for $q / l, k / l, \lambda$ and $n$ for given interest rates. This can be shown by substituting Equations (10) and (11) into (8).

$$
e^{c n} \frac{1-e^{-r n}}{r}-\frac{1-e^{-(r-c) n}}{r-c}=\frac{e^{c n}}{\left[\frac{A^{\rho} r}{(1-\delta)\left(1-e^{-r n}\right)}\right]^{1 /(1+\rho)}}
$$

Mapping $r$ onto $n$, it is shown in Figure 4 that the expected lifetime, $n$ will get a unique value, for specific interest rates when $c, \rho, \delta$ and $A$ are given. (10)

This means that $q / l$ will be determined by Equation

$$
q / l=w e^{c n}
$$

$k / l$ will then be determined by (11)

$$
k / l=\frac{q / l}{\left[\frac{A^{\rho} r}{(1-\delta)(1-e)^{-r n}}\right]^{1 /(1+\rho)}}
$$

and lastly $\lambda$ uniquely determined by (9).

$$
q / l=A\left[(1-\delta)(k / l)^{-\rho}+\delta\left(e^{\lambda}\right)^{-\rho}\right]^{-1 / \rho}
$$

The model can, thus, be seen as a recursively determined system.

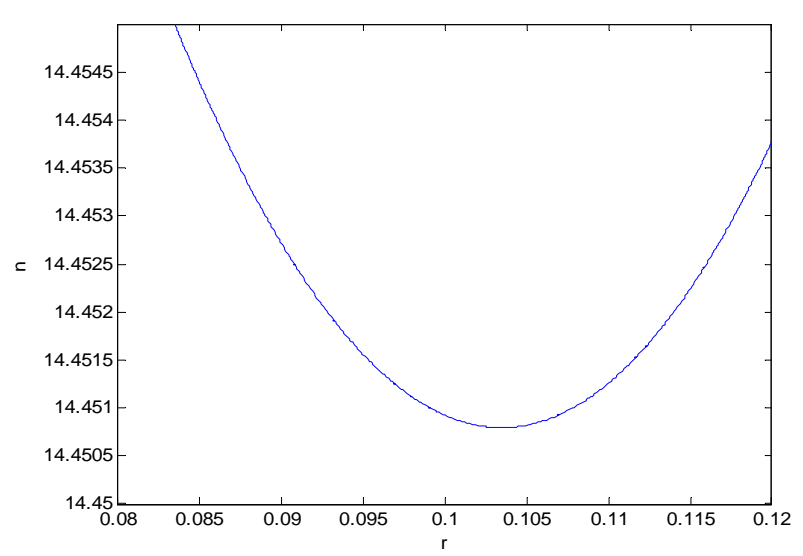

Figure 4. The expected length life of an investment. Note: $A$ $=1, \rho=0.38, \delta=0.6, c=0.04$. 


\section{Comparative Statics}

\section{Changes in the Interest Rate}

An increase in the interest rate will influence the four endogenous variables in the model. When performing comparative statics, there is a possibility to use analytical as well as numerical methods to show both sign and magnitude of the comparative statics derivatives.

This part will not only include comparative statics analysis on the endogenous variables, but also on the marginal product of capital and labour. Section 4 also investigates the conditions for the existence of turning points for expected lifetime, labour productivity and capital intensity when the interest rate increases.

\section{The Results and Discussion}

\subsection{Effects on the Expected Length Life of an Investment}

The effects of an increased interest rate on the expected length life of the investment can be studied more thoroughly by examining Equation (13).

$$
e^{c n} \frac{1-e^{-r n}}{r}-\frac{1-e^{-(r-c) n}}{r-c}=\frac{e^{c n}}{\left[\frac{A^{\rho} r}{(1-\delta)\left(1-e^{-r n}\right)}\right]^{1 /(1+\rho)}}
$$

For given values for $r, c, \rho, \delta$ and $A$, Equation (13) gives unique solution for $n$ and Figure 4 shows a mapping of $r$ onto $n$. The graph and simulations of the system of Equations (8)-(11) indicate that there is a turning point for the expected lifetime at 14.45 years when $r=0.104$ and $\rho=0.38$. There is thus a reswitching phenomenon concerning the expected lifetime.

However, when the substitution parameter changes, there will be different turning points for the expected lifetime. The effects of an increased interest rate at different values of the elasticity of substitution will be discussed in Sections 4.2-4.4.

\subsection{Effects on Labour Productivity and Capital Intensity}

In the previous section the first-order condition for an optimal lifetime for the investment was derived.

$$
q / l=w e^{c n}
$$

Assuming that $q / l$ and $n$ are functions of $r$ and differentiation of (3) yields

$$
\frac{\mathrm{d}(q / l)}{\mathrm{d} r}=c w e^{c n} \frac{\mathrm{d} n}{\mathrm{~d} r}
$$

This implies that

$$
\frac{\mathrm{d}(q / l)}{\mathrm{d} r}\left\{\frac{\geq}{\leq}\right\} 0 \text { when } \frac{\mathrm{d} n}{\mathrm{~d} r}\left\{\frac{\leq}{\geq}\right\} 0
$$

The productivity can rise, stay constant or decrease when the interest rate increases and the outcome depends on the value of the substitution parameter.

The effects of an increased interest rate on the capital intensity of a new investment can be found by examining Equations (10) and (11).

$$
k / l=w e^{c n}\left[(1-\delta) \frac{1-e^{-r n}}{A^{\rho} r}\right]^{1 /(1+\rho)}
$$

Let $k / l=k / l(r, n(r))$ and differentiation with respect to $r$ gives

$$
\frac{\mathrm{d}(k / l)}{\mathrm{d} r}=\frac{\partial(k / l)}{\partial r}+\frac{\partial(k / l)}{\partial n} \frac{\mathrm{d} n}{\mathrm{~d} r}
$$

The total effect on $k / l$ depends on a direct effect, $\frac{\partial(k / l)}{\partial r}$, and an indirect effect, $\frac{\partial(k / l)}{\partial n} \frac{\mathrm{d} n}{\mathrm{~d} r}$.

Differentiation of Equation (14) shows that the partial derivatives $\frac{\partial(k / l)}{\partial r}<0$ and $\frac{\partial(k / l)}{\partial n}>0$. It has in a previous section been shown that $\frac{\mathrm{d} n}{\mathrm{~d} r}\left\{\frac{\leq}{\geq}\right\} 0$. The indirect effect can, thus, reinforce or diminish the direct effect on the capital intensity. This outcome can also be described in a graphical way and Figure 5 shows Equation (14).

$$
\text { Figure } 5 \text { shows that } \frac{\partial(k / l)}{\partial r}<0 \text { and } \frac{\partial(k / l)}{\partial n}>0 \text {. }
$$

When the substitution parameter increases, the plane in the figure becomes flatter and this means that $\frac{\mathrm{d} n}{\mathrm{~d} r}$ will be crucial for the sign of $\frac{\mathrm{d}(k / l)}{\mathrm{d} r}$. An increased substi-

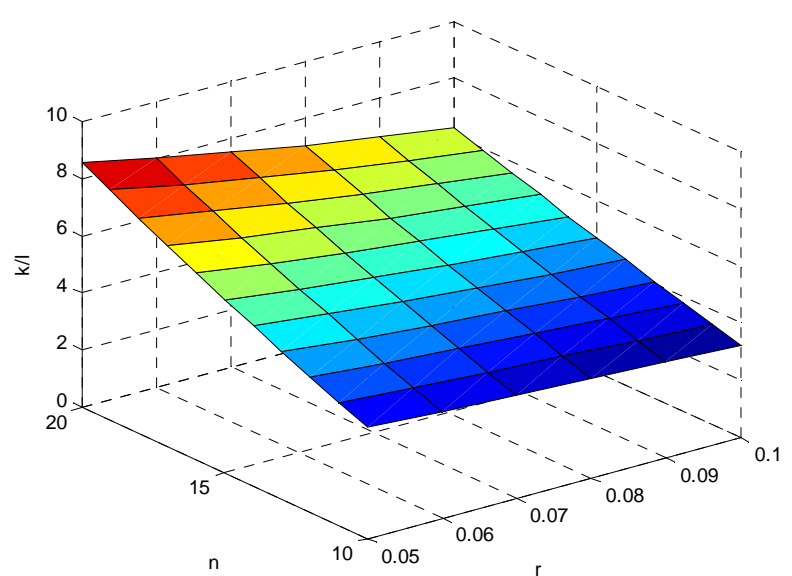

Figure 5. Capital intensity, expected lifetime and interest rate. Note: $w=1, r=0.10, A=1, \rho=0.2, \delta=0.6, c=0.04$. 
tution parameter, that is, a lower elasticity of substitution implies a lower substitutability in production. At high substitutability an increased interest rate will decrease capital intensity, while an opposite change for the factor intensity can occur at lower substitutability in production. There is thus a second reswitching phenomenon and in this case it concerns the factor intensity.

\subsection{Effects on Marginal Product of Capital and Investigation of Turning Points for Expected Lifetime, Labour Productivity and Capital Intensity}

The effects of a higher interest rate on the marginal product of capital at different elasticity of substitution can be investigated by Equation (5).

Equation (5) can be written

$$
\operatorname{MPK}=\frac{(1-\delta)}{A^{\rho}}\left(\frac{q / l}{k / l}\right)^{1+\rho}=\frac{r}{1-e^{-r n}}
$$

Mapping $n$ onto $r$ shows that RHS of (16) is decreasing in $n$ and the curve will shift upwards when the interest rate rises. This outcome is shown in Figure 6.

The graph indicates that MPK is affected partly by the interest rate, partly by the expected lifetime. Let MPK $=f(r, n(r))$ and differentiation of (16) with respect to $r$ gives:

$$
\frac{\mathrm{dMPK}}{\mathrm{d} r}=\frac{\partial f}{\partial r}+\frac{\partial f}{\partial n} \frac{\mathrm{d} n}{\mathrm{~d} r}
$$

Differentiation of (16) shows that $\frac{\partial f}{\partial r}>0$ and $\frac{\partial f}{\partial n}<0$.

It has been shown in Section 4.1 that the effect on expected lifetime is ambiguous when the interest rate rises.

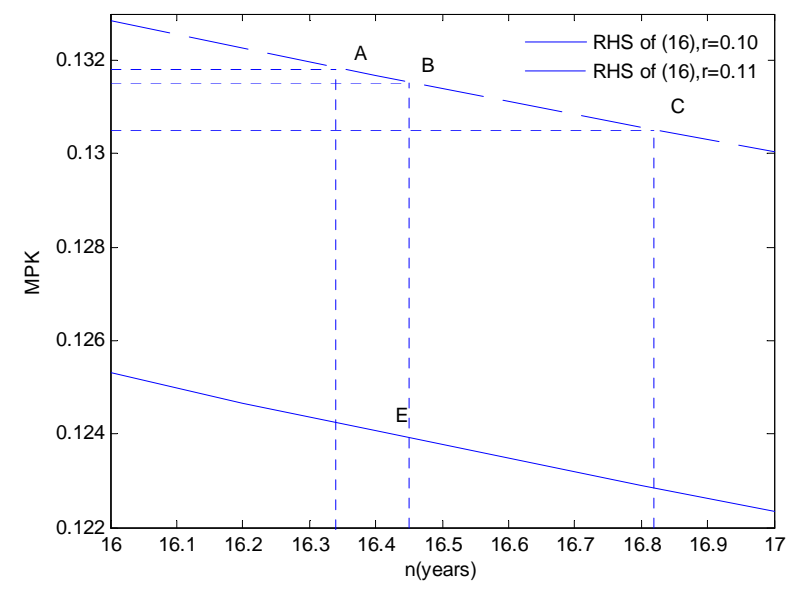

Figure 6. Changes in the interest rate and effects on MPK (calibrated model). At $\mathrm{E}$ (benchmark equilibrium): $r=0.10$, $\rho=0.20,0.38$ or 2.6, MPK $=0.1239, n=16.45$; At A: $r=$ 0.11, $\rho=0.20, \mathrm{MPK}=0.1318, \mathrm{n}=16.34$; At B: $r=0.11, \rho=$ 0.38, $\mathrm{MPK}=0.1314, n=16.45$; At C: $r=0.11, \rho=2.60$, MPK $=0.1305, n=16.82$.
This means that the effect on MPK will depend on the sign and magnitude of $\frac{\partial n}{\partial r}$.

Furthermore, assuming that $q / l$ and $k / l$ are functions of $r$, differentiation of the LHS of (16) with respect to $r$ gives

$$
\frac{\mathrm{d} \text { MPK } / \mathrm{d} r}{\operatorname{MPK}}=(1+\rho)\left[\frac{\mathrm{d}(q / l) / \mathrm{d} r}{q / l}-\frac{\mathrm{d}(k / l) / \mathrm{d} r}{k / l}\right]
$$

A profit maximizing firm tend to raise the marginal product of capital when the interest rate rises. A higher MPK requires that

$$
\left[\frac{\mathrm{d}(q / l) / \mathrm{d} r}{q / l}>\frac{\mathrm{d}(k / l) / \mathrm{d} r}{k / l}\right]
$$

The change in MPK for a given change in the interest rate will thus depend on the substitutability in production, but also of the change in lifetime of the capital good.

To compare the effects of a higher interest rate at different elasticities of substitution, the model is calibrated in order to eliminate different levels effects on endogenous variables. The parameters $A$ and $\delta$ in the production function are calibrated to a benchmark equilibrium for $n, q / l, k / l$ and $\lambda$ and this means that the effect of a change in $r$ on the endogenous variables is only due to a substitution effect.

In Figure 6 three different changes in MPK are indicated and the differences arise because of different values of the substitution parameter.

\subsubsection{Case A}

A higher interest rate raises the marginal product of capital and in case A this effect is reinforced by the decrease in lifetime. In Section 4.1 the following relationship was derived:

$$
\frac{\mathrm{d}(q / l)}{\mathrm{d} r}\left\{\frac{\geq}{\leq}\right\} 0 \text { when } \frac{\mathrm{d} n}{\mathrm{~d} r}\left\{\begin{array}{l}
\underline{\leq} \\
\geq
\end{array}\right\} 0
$$

The decline in lifetime implies that labour productivity will decline and Equation (17) then implies that the capital intensity has to decrease in order to raise the marginal product of capital.

Differentiation of the production function (9) gives the opportunity to study the effects on the labour-augmenting factor, $\lambda$.

$$
\frac{\mathrm{d}(q / l) / \mathrm{d} r}{(q / l)^{1+\rho}}=(1-\delta) \frac{\mathrm{d}(k / l) / \mathrm{d} r}{(k / l)^{1+\rho}}+\delta \frac{\mathrm{d}\left(e^{\lambda}\right) / \mathrm{d} r}{\left(e^{\lambda}\right)^{1+\rho}}
$$

When the productivity as well as the capital intensity fall, Equation (18) indicates that the effects of a higher interest rate on the technical progress factor, $\lambda$, are ambiguous. 
This case occurs when the value of the substitution parameter is zero or close to the Cobb-Douglas case and the substitutability in production is fairly high.

\subsubsection{Case B}

In this case there is no change in lifetime or labour productivity, but there is a positive effect on the marginal product of capital. In order to raise the marginal product of capital the capital intensity has to decline and Equation (18) then implies that the labour-augmenting factor has to increase.

In case B there is a turning point for $n$ and $q / l$. The substitution parameter has increased and the substituteability in production has decreased. In terms of equation (14) and the graph in Figure 5, the effects on the capital intensity will be smaller for a given change in the interest rate, which means that the effect on the marginal product of capital will be smaller.

\subsubsection{Case C}

The third case shows a situation where there is no change in factor intensity, implying that there is a turning point for $k / l$. This means that the capital intensity shows the same value at point $E$ and point $C$ in Figure 6.

According to Equation (17) a constant capital intensity and a higher productivity, due to a higher lifetime, leads to higher marginal product of capital. Lastly, a higher Harrod-neutral technical progress requires because of Equation (18).

When the production function is closer to the fixed proportion case the plane in Figure 5 become flatter, which means that a constant factor intensity requires a higher lifetime for the investment when the interest rate rises.

\subsection{Effects on Marginal Product of Labour}

The model gives also a possibility to investigate the effect on the marginal productivity of labour at different values for the substitution parameter when the interest rate rises.

Equation (7) can be written

$$
\mathrm{MPL}=\frac{\delta\left(\frac{q}{l}\right)^{1+\rho}}{\left(A e^{\lambda}\right)^{\rho}}=w \frac{\frac{1-e^{-(r-c) n}}{r-c}}{\frac{1-e^{-r n}}{r}}
$$

The RHS of (19) is increasing in $n$ and mapping $n$ onto $r$ shows that the curve will shift downwards when the interest rate rises. In Figure 7 the interest rate rises from 0.10 to 0.11 and the effects on MPL and $n$ are shown for three different values for the substitution parameter in a calibrated model.

These three optimal situations, D, F and G, coincide

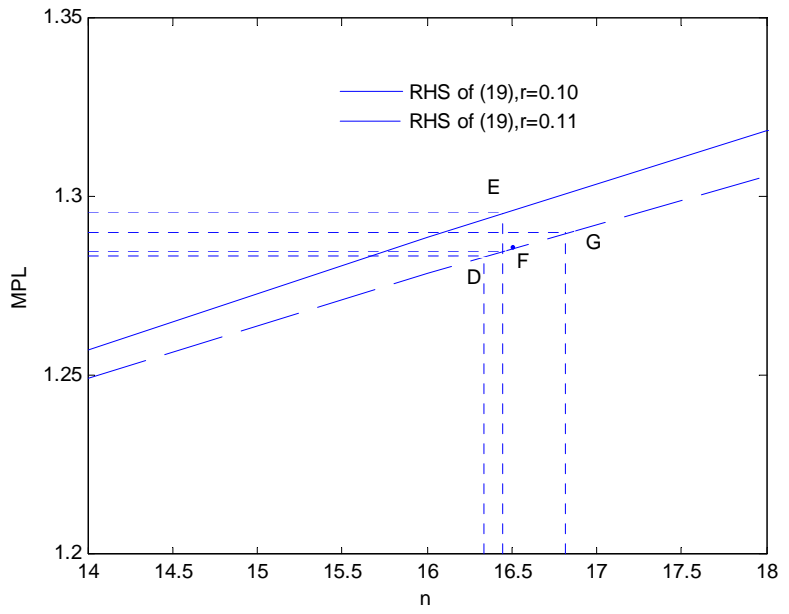

Figure 7. Changes in the interest rate and the effects on MPL (calibrated model); At $\mathbf{E}$ (benchmark equilibrium): $r$ $=0.10, \rho=0.20,0.38$ or 2.6, $\mathrm{MPL}=1.2957, n=16.45$; At $\mathrm{D}$ : $r=0.11, \rho=0.20, \mathrm{MPL}=1.2835, n=16.34$; At F: $r=0.11, \rho$ $=0.38, \mathrm{MPL}=1.2850, n=16.45$; At G: $r=0.11, \rho=2.60$, MPL $=1.2899, n=16.82$.

with $\mathrm{A}, \mathrm{B}$ and $\mathrm{C}$ in the previous section.

In case $\mathrm{D}$ the lifetime as well as the productivity will decrease. The marginal product of labour will decline and the decline will be reinforced by a lower lifetime.

The effect on the technical progress is ambiguous and this outcome can be derived from Equation (19). Differentiation of Equation (19) yields

$$
\frac{\mathrm{d} \text { MPL } / \mathrm{d} r}{\mathrm{MPL}}=(1+\rho) \frac{\mathrm{d}(q / l) / \mathrm{d} r}{(q / l)}-\rho \frac{\mathrm{d}\left(e^{\lambda}\right) / \mathrm{d} r}{e^{\lambda}}
$$

A lower MPL and $q / l$ imply then that the change in $\lambda$ can increase, stay constant or decrease.

In case $\mathrm{F}$ the lifetime and labour productivity are constant, but in this case the technical progress has to increase because of the lower marginal product of labour.

In the last case, where there is no change in factor intensity, the lifetime and productivity rise and there is a positive effect on the labour-augmenting factor, because of the production function or Equation (20).

\subsection{Summary of the Effects of a Rise in the Interest Rate}

The effects of an increased interest rate in a model with endogenous technical progress are presented in Table 1. The effects are calculated in a calibrated model and numerical simulations are made for the system of Equations (8)-(11).

Turning points are found for $n, q / l$ and $k / l$ and it means that in the neighbourhood of these turning points the model will generate reswitching phenomenon for the mentioned endogenous variables. 
Table 1. Effects of an increased interest rate and turning points for $n, q / l$ and $k / l$ (calibrated model).

\begin{tabular}{ccccccccc}
\hline & & \multicolumn{3}{c}{ Effects on } & & & & \\
& & $q / l$ & $k / l$ & $\lambda$ & $n$ & MPK & MPL \\
\hline 1$)$ & $\rho_{1}=0$ (Cobb-Douglas case) & neg & neg & pos & neg & pos & neg \\
$2)$ & $\rho_{2}=0.38$ & turning point & neg & pos & turning point & pos & neg \\
$3)$ & $\rho_{3}=2.6$ & pos & turning point & pos & pos & pos & neg \\
\hline
\end{tabular}

Note: $w=1, c=0.04, r$ changes from 0.10 to 0.11 .

\subsection{Comparison with a Model Including a Constant Labour-Augmenting Factor}

Lastly, there is of some interest to make a comparison between the model with endogenous technical progress and a model with an exogenous and constant labouraugmenting factor.

The first-order condition (7) for an optimal labour input is

$$
\frac{\delta(q / l)^{1+\rho}}{\left(A e^{\lambda}\right)^{\rho}} \int_{t}^{t+n} e^{-r(v-t)} \mathrm{d} v=w \int_{t}^{t+n} e^{-(r-c)(v-t)} \mathrm{d} v
$$

Substituting (10) into (7) the first-order condition becomes

$$
\frac{\delta\left(w e^{c n}\right)^{1+\rho}}{\left(A e^{\lambda}\right)^{\rho}}=w \frac{\frac{1-e^{-(r-c) n}}{r-c}}{\frac{1-e^{-r n}}{r}}
$$

A graphical solution of (21) is shown in Figure 8 and the expected lifetime, $n$, will get unique values for specific interest rates when $c, \rho, \delta$ and $A$ are given.

Let

$$
\operatorname{MPL}(n)=\frac{\delta\left(w e^{c n}\right)^{1+\rho}}{\left(A e^{\lambda}\right)^{\rho}}
$$

and

$$
C W=w \frac{\frac{1-e^{-(r-c) n}}{r-c}}{\frac{1-e^{-r n}}{r}}
$$

Given the equilibrium for the expected lifetime, $n$, the capital intensity and the productivity level at the current period as well as the marginal productivities can be calculated.

An increased interest rate will decrease the expected lifetime of the investment as well as the factor intensity in the current period. This means also that the productiveity in the current period will decrease. The effects of these changes are that the marginal productivity of capital will increase, while the marginal productivity of la- bour will decrease. The effects of a change in the interest rate or the wage rate on factor productivity, factor intensity and expected lifetime of an investment are discussed in a more formal way in Melén [27].

Table 2 gives a summary of the effects of an increased interest rate and contrary to the case with a variable labour-augmenting factor, there are no turning points at different values of the elasticity of substitution when the labour-augmenting factor is constant.

There is a dramatic change of the effects of an increased interest rate when the technical progress becomes endogenous and variable. Firstly, the expected lifetime of the investment will not decrease but increase at a certain level of the elasticity of substitution. Secondly, the productivity of labour and the capital intensity at the current period will be increasing in the interest rate when the substitutability between labour and capital becomes smaller.

This outcome can be seen as an example of a reswitching process. For low values of the elasticity of

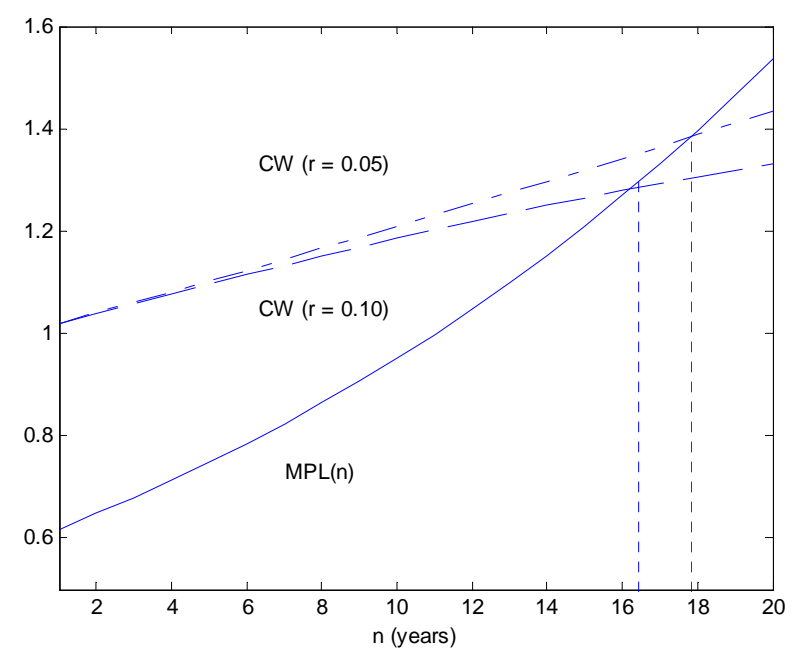

Figure 8. Effects of a change in the interest rate with a constant labour-augmenting factor ${ }^{4}$. Note: $w=1, \delta=0.6, c=$ $0.04, e^{\lambda}=1.10, \rho=0.2, A=1$.

\footnotetext{
${ }^{4}$ The intercepts in Figure 8 are $\frac{\delta}{\left(A e^{\imath}\right)^{\rho}}$ for $M P L(n)$ and $w$ for

$C W$ and the intercept for CW can be found by using L'Hopital's rule.
} 
Table 2. Effects ${ }^{5}$ of an increased interest rate when the labour-augmenting factor is constant.

\begin{tabular}{ccccccc}
\hline \multicolumn{7}{c}{ Effects on } \\
$q / l$ & $k / l$ & $\lambda$ & $n$ & MPK & MPL \\
\hline neg & neg & constant & neg & pos & neg \\
\hline
\end{tabular}

substitution, an increase in the interest rate or the factor price ratio (wages are constant), will generate a turning point for the factor intensity, while at a higher elasticity of substitution an equal change in the interest rate, will generate a turning point for the productivity. The main explanation to this outcome is the change in Harrodneutral progress, which is increasing in the interest rate.

When there is no technical progress there will be no reswitching process. An increased interest rate implies a higher marginal product of capital, which can be explained by diminishing returns to capital, and a lower expected lifetime of the investment.

\section{Conclusions}

The study shows that the effects of an increase in the interest rate to a large extent depend on the value of the elasticity of substitution in production when the Harrod-neutral technical progress is endogenous and variable.

One of the results of this study is that the expected length of life of an investment will either increase or decrease when the interest rate increases.

The second important result is that an increase in the interest rate can cause an increase in the productivity of the new investment at the current period.

The most important result is that an increase in the interest rate can cause an increased capital intensity when the elasticity of substitution falls and becomes low. The last result indicates that the model generates a reswitching process, which means that under certain conditions the demand for capital is increasing in the interest rate. However, a more rigorous test of the model would be to make an empirical investigation of the investment behavior of firms with different technological characteristics, such as high or low substitution possibilities in production.

\section{Acknowledgements}

I am grateful to Lars Hultkrantz, Chuan-Zhong Li and Niklas Rudholm for valuable comments and important remarks on earlier versions. Seminar participants at Örebro university and Dalarna university have provided valuable comments on previous drafts of the manuscript. All remaining errors are my responsibility.

${ }^{5}$ Refers to cases when second-order conditions for profit maximization hold.

\section{REFERENCES}

[1] J. Haltiwanger, J. Lane and J. Speltzer, "Productivity Differences across Employers: The Roles of Employer Size, Age, and Human Capital," American Economic Review, Vol. 89, No. 2, 1999, pp. 94-98. doi:10.1257/aer.89.2.94

[2] M. Baily, E. Bartelsman and J Halltiwanger, "Labor Productivity: Structural Change and Cyclical Dynamics," Review of Economics and Statistics, Vol. 83, No. 3, 2001, pp. 420-433. doi:10.1162/00346530152480072

[3] C. Papageorgiou and M. Saam, "Two-Level CES Production Technology in the Solow and Diamond Growth Models,” Discussion Paper, Department of Economics, Louisiana State University, Baton Rouge, Vol. 2005-2007, 2005.

[4] R. Klump and O. De La Grandville, "Economic Growth and the Elasticity of Substitution: Two Theorems and Some Suggestions," American Economic Review, Vol. 90, No. 1, 2000, pp. 282-291. doi:10.1257/aer.90.1.282

[5] K. Miyagiwa and C. Papageorgiou, "Endogenous Aggregate Elasticity of Substitution," Journal of Economics and Dynamics, Vol. 31, No. 6, 2007, pp. 2899-2919. doi:10.1016/j.jedc.2006.06.009

[6] J. Duffy and C. Papageorgiou, “A Cross-Country Empirical Investigation of the Aggregate Production Function Specification,” Journal of Economic Growth, Vol. 5, No. 1, 2000, pp. 87-120. doi:10.1023/A:1009830421147

[7] C. M. Pereira, "Variable Elasticity of Substitution, Technical Change, and Economic Growth," Working Paper, Department of Economics, North Carolina State University, Raleigh, 2004.

[8] K. J. Arrow, H. B. Chenery, B. S. Minhas and R. M. Solow, "Capital-Labor Substitution and Economic Efficiency," Review of Economics and Statistics, Vol. 43, No. 3, 1961, pp. 225-250. doi:10.2307/1927286

[9] N. Kaldor, "Capital Accumulation and Economic Growth," In: E. A. Lutz and D. C. Hague, The Theory of Capital, St. Martins Press, New York, 1961, pp 177-222.

[10] E. R. Berndt, "Reconciling Alternative Estimates of the Elasticity of Substitution," Review of Economics and Statistics, Vol. 58, No. 1, 1976, pp. 59-68. doi:10.2307/1936009

[11] S. Gilchrist and J. C. Williams, "Investment, Capacity and Output: A Putty-Clay Approach,” Federal Reserve Board, Washington, DC, 1998.

[12] L. Johansen, "Substitutions versus Fixed Production Coefficients in the Theory of Economic Growth: A Synthesis,” Econometrica, Vol. 27, No. 2, 1959, pp. 157-176. doi:10.2307/1909440

[13] M. Lasky, "A Putty-Clay Model of Business Fixed Investment,” CBO Technical Paper, Washington, 2003.

[14] W. E. G. Salter, "Productivity and Technical Change," Cambridge University Press, Cambridge, 1960.

[15] R. M. Solow, "Substitution and Fixed Proportion in the Theory of Capital,” Review of Economic Studies, Vol. 29, No. 3, 1962, pp. 207-218. doi:10.2307/2295955 
[16] H. D. Kurz, Ed., “Critical Essays on Piero Sraffa’s Legacy in Economics," Cambridge University Press, Cambridge, 2000.

[17] J. Robinson, “The Production Function and the Theory of Capital," Collected Economic Essays, Oxford Unversity Press, Oxford, Vol. 2, 1960.

[18] P. A. Samuelson, "Parable and Realism in Capital Theory: The Surrogate Production Function,” Review of Economic Studies Vol. 29, No. 3, 1962, pp. 193-206. doi: $10.2307 / 2295954$

[19] Z. Han and B. Schefold, “An Empicical Investigation of Paradoxes: Reswitching and Reverse Capital Deepening in Capital Theory," Cambridge Journal of Economics, Vol. 30, No. 5, 2006, pp. 737-765. doi:10.1093/cje/bei089

[20] D. Acemoglu, "Equilibrium Bias of Technology,” Econometrica, Vol. 75, No. 5, 2007, pp. 1371-1410. doi:10.1111/j.1468-0262.2007.00797.x

[21] J. R. Hicks, “The Theory of Wages,” St. Martins Press, New York, 1932.

[22] S. Ahmad, "On the Theory of Induced Innovation," Eco- nomic Journal, Vol. 76, 1966, pp. 344-357. doi: $10.2307 / 2229720$

[23] Y. Hayami and V. W. Ruttan, "Agricultural Development: An International Perspective,” 2nd Edition, Johns Hopkins University Press, Baltimore, 1985.

[24] C. G. Thirtle, "The Microeconomic Approach to Induced Innovation: A Reformulation of the Hayami and Ruttan Model," Manchester School of Economic and Social Structure, Vol. 53, No. 3, 1985.

[25] R. Esposti and P. Pierani, "Price-Induced Technical Progress in Italian Agriculture," Review of Agricultural and Environmental Studies, INRA Department of Economics, Vol. 89, No. 4, 2008, pp. 5-28.

[26] Q. Paris, "Price-Induced Technical Progress in 80 Years of US Agriculture," Journal of Productivity Analysis, Vol. 30, No. 1, 2008, pp. 29-51. doi:10.1007/s11123-008-0083-9

[27] C.-G. Melén, “A Note on Factor Prices and Technical Progress,” Technology and Investment, Vol. 2, No. 3, 2011, pp. 202-210. doi:10.4236/ti.2011.23021 